\title{
Los complejos habitacionales Fonavi en la construcción del territorio urbano
}

\author{
Silvana Martino \\ Centro Internacional Franco Argentino de Ciencias de la \\ Información y de Sistemas (Cifasis)
}

\section{Los complejos habitacionales Fonavi en la construcción del territorio urbano}

Resumen: El presente artículo se propone analizar la política habitacional Fonavi en un complejo habitacional y los modos en que esta misma política construye y construyó espacios dentro de la trama urbana. Se parte de describir la historia de dicha construcción, las trayectorias ocupacionales de quienes allí habitan, en tanto construcción de la territorialidad, para luego ir desentrañando los modos de participación en su interior y los espacios institucionales con los que cuentan. Se pondrá especialmente énfasis en describir y analizar una de sus instituciones, los consorcios, en tanto espacio de administración de lo común. Desde allí se analizan las relaciones de poder que se van construyendo el interior del barrio, lo cual permite leer una heterogeneidad de espacios y lugares

Palabras claves: Política habitacional. Espacio social. Estigmatización. Construcción de territorios urbanos.

\section{Os complexos habitacionais Fonavi na construção do território urbano}

Resumo: Este artigo propõe-se a analisar a política habitacional Fonavi em um complexo habitacional e como esta mesma política vem construindo espaços dentro da trama urbana. Inicia descrevendo a história do empreendimento, as trajetórias dos que ali habitam, quanto à construção da territorialidade, para depois ir desentranhando os modos de participação em seu interior e os espaços institucionais disponíveis. Enfatiza a descrição e a análise em uma de suas instituições, os consórcios, como espaço de administração do comum. A partir deles, são analisadas as relações de poder que se vão construindo no interior do bairro, as quais permitem observar uma heterogeneidade de espaços e lugares.

Palavras-chave: Política habitacional. Espaço social. Estigmatização. Construção de territórios urbanos.

\section{The Fonavi Housing Complexes in the Construction of Urban Territory}

Abstract: This article analyzes the Fonavi housing policy at a housing complex and the ways that this policy constructs and constructed spaces within urban regions. It begins by describing the history of this construction and the occupational trajectories of those who inhabit it, in terms of construction of territoriality. It then untangles the modes of participation at its interior and the institutional spaces on which it counts. It places particular emphasis on describing and analyzing one of the institutions, the consortiums, as a space for administration of the common. It then analyzes the power relations that are constructed at the interior of the neighborhood, which allows reading a heterogeneity of spaces and places.

Key words: Housing policy. Social space. Stigmatization. Construction of urban territory. 


\section{Introducción}

En el presente artículo ${ }^{1}$ nos proponemos analizar la política habitacional Fondo Nacional de la Vivienda (Fonavi) en un complejo habitacional en particular, al que llamaremos aquí El Matadero, y los modos en que esta misma política construye y construyó espacios dentro de la trama urbana.

Actualmente, estos complejos habitacionales en todo el territorio argentino constituyen conjuntos diferenciados o periféricos, con características que hacen que tanto la gente que habita el complejo como la que no, lo nombre como un barrio autónomo, lo cual es ayudado por su densidad poblacional y contrastado diseño cerrado. Estos aspectos segregatorios, sintetizados como diferencia tipológica con respecto al resto de la ciudad y su homogeneidad interna, en tanto se repiten las figuras y estilos a lo largo de todo el complejo, no logra cristalizarse en una forma sólo arquitectónica, sino son las relaciones sociales las que cotidianamente rompen, y de manera conflictiva, esa uniformidad.

Estas relaciones se condensan en las formas particulares de participación entre los vecinos, las organizaciones de tipo vecinal, y las instituciones.

El Fondo Nacional de Vivienda (en adelante Fonavi) como política habitacional se constituyó en un programa oficial mediante el cual se diseñaron y construyeron los conjuntos habitacionales. Originariamente surge a través de la Ley n. 21.581/1977², con el objetivo de reactivar el mercado al que se ligaban los sectores privados de la construcción y entidades financieras. Esto se ha constituido en un tipo de oferta particular desde el Estado en alianza con grupos económicos que promovió la construcción de los conjuntos habitacionales y el acceso a la vivienda para grupos poblaciones que quedaban fuera del sistema de préstamos privados.

A partir de las trayectorias ocupacionales, los modos en que los distintos habitantes y agentes fueron apropiándose de la política Fonavi en las prácticas concretas de estos barrios, encontré singularidades densas de una misma política, lejos, en muchos casos, de la aplicación de una normativa universal/nacional, y sistemática.

Entendemos que toda espacialidad en el ámbito urbano no es un dato dado, natural, sino más bien una construcción fuertemente social y simbólica, donde los agentes que allí intervienen (vecinos, gestiones de gobierno, empresarios etc.) luchan por dotar a ciertos territorios de una representación que imprima distintos sentidos al vivir allí, como así también su vinculación a la trama de la ciudad a la que pertenece.

Estas construcciones no se dan de una vez para siempre, sino que son parte de conflictos, tensiones entre, el barrio y la ciudad; o al interior del mismo barrio, en las múltiples divisiones por zonas. Por esto se vuelve imprescindible conocer los relatos y los puntos de vista que participan en dicha construcción, para poder comprender los mapas, las cartografías vinculares y su constante lucha por imponer una determinada representación social de ese lugar.

\section{De la construcción de la territorialidad}

La construcción de los complejos habitacionales se encuentra situada mucho antes que el Fonavi empezara concretamente a trabajar allí, es decir, el proceso de apropiación de la vivienda como tal comienza desde que cada una de las familias decide conseguir una vivienda.

En el conjunto habitacional analizado, aparecen trayectorias ocupacionales y actores intervinientes que marcan una diferencia importante dentro de una misma política, desde el mismo momento de la tramitación y gestión de la vivienda. En este punto, me interesó poner el foco no en las características edilicias de la vivienda en sí, en tanto arquitectura física que la propia política instauraba, sino más bien, la relación que guardan los habitantes y los no habitantes con ellas, relaciones mediadas por la ideología y experiencia biográfica y de éstos entre sí.

Así, como lo advierte Reguillo, tanto quienes habitan estos conjuntos como los que no, elaboran mapas subjetivos de la ciudad imaginada que repercuten fuertemente en la ciudad practicada (CERTEAU, 1996 apud REGUILLO, 2005), a partir de los cuales estos conjuntos habitacionales se incluyen simbólicamente en el entramado urbano.

Siguiendo a Reguillo (2005, p. 5), no hay territorio sin actores. Esto implica que

[...] toda interpretación que se haga de un lugar se produce desde un lugar, lo cual obliga a considerar las diferencias y similitudes perceptivas e interpretativas que, más allá de la afirmación de las muchas ciudades que hay en una ciudad, involucra relaciones de poder, procesos de adscripción cultural e identitaria, memoria y competencias diferenciadas de lectura, de cuya articulación se desprenden los mapas. Así la pregunta por el 'quién' percibe, interpreta y actúa no es secundaria.

Por un lado, entonces, está la construcción desde la "institución política", en el propio texto de la ley (Ley Fonavi, n. 21.581/1977) como en las circunstancias y momentos en los que se aprueba esa ley. Aquí no solo me interesa la norma o lo reglamentado sino los intereses, objetivos, y la coyuntura en la que surge. Por otro lado, los modos particulares de llevar y hacer una práctica institucional y política a partir de esa ley. Y por último, las trayectorias ocupacionales y estrategias de 
adquisición de los propios habitantes - beneficiarios de esa misma ley.

Las formas y trayectorias de las ocupaciones que los mismos habitantes le fueron imprimiendo son procesos que no se agotaron con la adquisición de la vivienda, sino, al decir de Giglia (1998), siguen aún y a su vez, empiezan mucho antes, con la gestión individual o colectiva, la tramitación, la lucha o negociación para la obtención del bien que estaba en juego. El recuperar estas trayectorias me permitió ir leyendo los sentidos que los ocupantes y las políticas les fueron imprimiendo al territorio, en tanto "efectos de lugar".

Actualmente es posible encontrar en la ciudad construcciones sociales acerca de estos lugares, los que aún siguen llamándose "guetos urbanos", acentuando con esto la significación de espacios de "encierro" de determinadas poblaciones que, por el hecho de co-residir, comparten algún estigma que los identifica del resto de la ciudad. La idea de gueto además implica una serie de características que no sólo homogeniza a la quienes allí residen, sino que también vuelve las relaciones en su interior desvinculadas a un afuera, construyéndose la imagen de una "ciudad dentro de otra".

En estas zonas, según Wacquant (2000), hoy se lleva adelante una política de mundialización de la "tolerancia cero" como instrumento de legitimación de la gestión policial y judicial de la pobreza que molesta. Esto le permite a la vez reafirmar a bajo costo la decisión del Estado de actuar con severidad frente a los desórdenes y liberar a ese mismo Estado de sus responsabilidades en la génesis social y económica de la inseguridad, para apelar a la responsabilidad individual de los habitantes de las zonas inciviles.

Wacquant (2001, p. 43-152) define a los guetos como espacios compactos, y marcadamente delimitado, con una formación racial y/o culturalmente uniforme basada en la relegación forzosa de una población negativamente tipificada a un territorio específico.

Este autor establece una diferencia entre los llamados guetos comunitarios de pos guerra y los hiperguetos de los 80 , definiendo estos cambios en relación a la desarticulación comunitaria que en los años anteriores le habían permitido politicizar los reclamos de las comunidades negras. Esta diferencia se basa sobre todo a la definición de un espacio urbano en donde las relaciones étnicas no es una de las características fundantes.

En contraposición a los planteos de este último autor, sostenemos que los espacios urbanos marginales, si bien son espacios sociales diferenciados del resto de la ciudad en tanto su forma física, y por la construcción de una "estigamtización" territorial negativa, no es posible analizarlos como espacios desvinculados de la trama política, social y económica de la sociedad, porque son los mismos habitantes quienes en su cotidianeidad establecen y sostiene lazos con ese "afuera", lo cual permea las prácticas y los discursos de "ese adentro" cada vez más difuso en sus límites. Es por esto que la idea de espacios cerrados o determinados y determinantes a priori no encuentra sustento en las prácticas cotidianas de quienes allí habitan.

Además, son las mismas instituciones al interior de estos espacios quienes posibilitan plantear esta doble mirada, en tanto que son ellas mismas, por un lado, expresiones particulares de una política más general, lo cual garantizaría al menos en términos de recursos, una vinculación con un "afuera"; y por otro pareciera que su misma presencia, muchas veces masiva, superponiéndose unas con otras, reproduce la construcción de categorías y clasificaciones de determinadas poblaciones, y así el "encierro" de estas en determinadas políticas focalizadas y diferenciadas.

El espacio social se retraduce, siguiendo a Bourdieu (1999), en el espacio físico, pero siempre de manera más o menos turbia: el poder sobre el espacio que da la posesión del capital en sus diversas especies se manifiesta en el espacio físico apropiado en la forma de determinada relación entre la estructura espacial de la distribución de los agentes y la estructura espacial de la distribución de los bienes y servicios, privados o públicos.

Debido al hecho, que el espacio social está inscripto a la vez en estructuras espaciales y las estructuras mentales, el espacio es uno de los lugares donde se afirma y ejerce el poder y sin duda en la forma más sutil, la de la violencia simbólica como violencia inadvertida: los espacios arquitectónicos son en verdad los componentes más importantes a causa de su misma invisibilidad de la simbólica del poder y de los efectos totalmente reales del poder simbólico (BOURDIEU, 1999).

Así, la estructura del espacio se manifiesta en los contextos más diversos, en la forma de oposiciones espaciales en las que el espacio habitado (o apropiado) funciona como una especie de simbolización espontánea del espacio social.

Por todo esto, nos interesó poder comprender como los barrios de Interés Social se fueron constituyendo en "lugares paradigmáticos" dentro de la ciudad. Lugares que si bien parecieran estar escindido por su singular diseño arquitectónico, marcando un "adentro y un afuera" de la trama de la ciudad se encuentran fuertemente vinculado a partir de las relaciones y vínculos que sus habitantes construyen a diario y esto a su vez, pone en tensión las representaciones negativas, con las que cargan estos territorios.

\section{Barrios de Interés Social: los complejos habitacionales Fonavi}

Llamamos Barrios de Interés Social a los complejos de vivienda colectiva construidos por políticas públicas, destinadas a grupos poblaciones que no tienen acceso al 
crédito privado. Su acceso no es masivo, en tanto existen reglamentos y requisitos formales que restringen el ingreso a dicho beneficio. También y así como lo refiere Giglia (1998), estos se diferencia de aquellas políticas habitacionales promovidas por los gobiernos en las cuales se prevé una relativa libertad y autonomía de los usuarios en cuanto a las formas y a los tiempos y las modalidades de su edificación, siendo la gestión de la misma política quien propone el lugar donde se emplazará el complejo como el diseño de construcción.

Específicamente es el Fonavi la política habitacional que sirvió de soporte para la construcción del complejo habitacional aquí estudiado, los cuales iniciaron su construcción en el año 1979, entregándose los primeros departamentos en 1981.

Es interesante no perder de vista el contexto donde surge dicha política. La dictadura militar de 1976 se traducía, en principio, como la imposibilidad política de los vecinos de decidir acerca del espacio barrial. Pero esta imposición, en tanto política habitacional, no consensuada por los vecinos y los funcionarios locales, se escenificaba en un contexto que tanto en el ámbito nacional como local, ya venía dejando marcas represivas imborrables en la ciudad aquí analizadas, bajo la máscara de la reorganización nacional.

La política habitacional no estaba ajena a dichos principios y herramientas utilizadas por la dictadura, por eso, tal como lo expresa Oslack (1985, p. 71):

[...] resultaría difícil comprender las orientaciones de política urbana del gobierno militar instalado en 1976, sin tomar en cuenta su particular concepción de orden social que aspiraba instituir, del lugar que en el mismo se asignaba a los sectores populares, del papel estratégico que tenía la ocupación del espacio geográfico y de la distribución poblacional juzgada más conveniente a los fines de la seguridad nacional.

Así, la operativa Fonavi, sancionada y promulgada como la Ley Nacional n. 21.581 el 26 de mayo de 1977, implicó la creación de un fondo de asignación específico destinado a la construcción de viviendas económicas, constituyéndose en una innovación en políticas de viviendas, que además permitía solapar los intereses privados con relación a la tierra como a la construcción. Esta ley se sanciona para reemplazar y modificar una ley Fonavi anterior (n. 19.929) la cual había sido promulgada en 1972. Entre una de las cuestiones objeto de reforma se encuentra la población objeto de tal política, y el paso de las responsabilidades a las provincias de su conducción.

\subsection{Complejo Habitacional El Matadero}

La propuesta de la Municipalidad de Mar del Plata sobre qué hacer en ese espacio físico urbano inserto en el Barrio Bernardino Rivadavia, dio lugar a que los vecinos agrupados en la Sociedad de Fomento de la zona (organización vecinal de fuerte y larga presencia en el barrio) y la Municipalidad comiencen a discutir. Así, es que empiezan a tejerse diferentes sentidos signados de intereses distintos también, en torno a ese espacio. Estas discusiones que de algún modo se constituyeron en luchas, que podríamos decir políticas, culminan, en ese espacio, con la implementación e imposición de una política habitacional a escala nacional.

Específicamente en Mar del Plata, esta política de vivienda fue la salida que se encontró, desde el nivel municipal, para dar solución a dos problemáticas urbanas con fuerte impacto social negativo, sobre todo para las zonas aledañas. Una era la existencia del basural y matadero municipal en el entramado urbano, y la otra la constitución de asentamientos irregulares en espacios casi urbanos y poblaciones con problemas habitacionales o con escasos accesos a la vivienda propia.

Frente a las quejas y reclamos de los vecinos se había comenzado a promover la participación de los que residían alrededor de esa zona conflictiva, a quienes se les propone en aquel momento elaborar un proyecto destinado al uso de ese espacio. Así es que se diseña y propone para dicho espacio una zona residencial, para, siguiendo con la estética de barrio obrero, integrarla a éste.

La existencia del basural y sobre todo del matadero (ambos municipales) irrumpiendo en el trazado del barrio, provocaba en los vecinos un gran malestar, "no era agradable vivir con la sangre bajando por las alcantarillas", lo cual unos años más tarde cobrará mayor relevancia cuando se sospeche que esa zona era utilizada como "enterratorio" de disidentes políticos.

No obstante, la Municipalidad decide instalar este tipo de construcción social en la ciudad de Mar del Plata sintiéndose, por consecuencia, defraudado el reclamo de los mismos vecinos. Este hecho tuvo un fuerte impacto en las relaciones entre los vecinos y el nuevo proyecto, al punto de diferenciar al complejo habitacional por años como un barrio independiente del Barrio Bernardino Rivadavia, lo que provocó que la población residente del complejo no sea incluida como partícipe ni beneficiaria de la Sociedad de Fomento de dicho barrio.

La selección de los beneficiarios estuvo en manos de la Municipalidad. La convocatoria fue abierta públicamente, disponiendo de un tiempo y un lugar, (un club cercano) para la realización de entrevistas personales. Estas estuvieron a cargo de asistentes sociales quienes evaluaron los ingresos y el tipo de familia.

Según la normativa, los sujetos evocados como destinatarios de la construcción de estas viviendas económicas fueron las familias de recursos insuficientes. Pero, en la realidad de dicho barrio, la selección 
respondió a una heterogeneidad de intereses. Se otorgaron los departamentos a familias inquilinas que vieron en esto la posibilidad de la casa propia, pero que no correspondían, por ejemplo, al nivel económico enunciado; otras que residían en barrios precarios, o villas de emergencias; maestros; los mismos que trabajaron en la construcción del complejo, tanto albañiles como profesionales etc.

Esta heterogeneidad complejiza desde entonces los procesos de socialización y la movilidad de los habitantes, lo que permitió romper con la homogeneización estática o de hormigón que se pretendía lograr en tanto grupo focalizado-estigmatizado, para constituirse en cambio en una heterogeneidad móvil y diferenciadora al interior del mismo complejo.

La existencia de otros espacios barriales dentro de la ciudad con características conflictivas más complejas pareciera no tener el mismo peso social en el imaginario ni en el discurso de la sociedad marplatense en lo que respecta, por ejemplo, a la inseguridad. Esto permite que "zonas conflictivas" dentro de la ciudad queden relativizadas por la magnitud edilicia y poblacional de El Matadero (en adelante EM).

Desde hace 50 años existe un asentamiento irregular a espaldas de EM con fuertes "desordenes", compartiendo de alguna manera el entramado de pasillos y laberintos propicios para el ocultamiento y el no-acceso desde el exterior. Este asentamiento precario se encuentra al oeste del complejo habitacional. El fundamento para su emplazamiento lo constituyó originariamente el basural municipal, que se encontraba radicado en el mismo terreno del complejo en donde trabajaban los distintos grupos que allí residen. Las familias que históricamente conforman este asentamiento no fueron objeto de la política habitacional, ni siquiera fueron entrevistadas para evaluar la posibilidad de ser beneficiarias de la vivienda. Esto nos permite poner entredicho el objetivo de la misma.

Actualmente no existe documentación sobre los avances técnicos del complejo de aquellos años, los cuales "no ingenuamente", según refiere el personal del mismo Instituto de la Vivienda, fueron quemados en las oficinas que ocupaban en dicho complejo, lo que redunda en el imaginario lo penumbroso que fue la construcción y todo lo que ella implicó. A su vez, esta ausencia de los originales y otros papeles que dan cuenta de los procesos de construcción se vuelve un obstáculo para cada familia residente a la hora de reclamar o protestar acerca de las malas condiciones técnicas de la construcción.

\subsection{Espacios, instituciones y participación}

Las divisiones y conflictos internos dentro de los mismos barrios son las que hacen de esos lugares, aparentemente homogéneos, un campo de poder, fragmentando en su interior distintos espacios sociales. Algunos de estos espacios son formales, correspondiendo a límites geográficos e institucionales, y otros informales, que no tienen una clara delimitación en tanto se van construyendo sus fronteras a partir de las relaciones entre los vecinos y entre éstos y las instituciones, excediendo el límite físico del complejo.

Así, en determinados espacios dentro de EM se llevan adelante prácticas que apuntan hacia la democratización, en tanto se valen de herramientas tales como las asambleas, o una participación más colegiada a la hora de tomar decisiones, o rotaciones de cargos en la administración; al lado de prácticas autoritarias, que niegan aquellas herramientas. Todo esto conviviendo en un mis-mo espacio.

Sabedores que estos procesos que se explicitan en este caso particular y que es posible encontrarlos en un nivel más general, van produciendo rupturas en las formas tradicionales de sociabilidad y los consecuentes procesos de fragmentación social, lo cual trae, como consecuencia, formas de discriminación simbólica o cultural de determinana dos sujetos y espacios.

Las relaciones de sociabilidad que se establecen al interior de los enclaves urbanos se encuentran hoy enmarcadas en un proceso de degradación relativa de las tradicionales formas de sociabilidad, solidaridad y reciprocidad (PUEX, 2003; ROSSINI, 2003). Éstas se ven afectadas por determinados grupos que desafían tradicionales formas de convivencia, vulnerando reglas de uso y costumbre en esos ámbitos como no robar dentro del propio barrio o evitar el uso irracional de violencia (KESSLER, 2002).

Por esto nos pareció interesante incluir la perspectiva que se construye desde un afuera, como un punto de vista externo, donde es posible encontrar en dicha visión una percepción del adentro como una totalidad 
homogénea, incluida en los límites físicos del propio complejo habitacional. Así, tomando a Puex (2003, p. 41), se llama territorialización a este proceso de identificación y estigmatización negativa y violenta de un territorio determinado adentro del espacio urbano, conduciendo a relaciones y prácticas discriminantes en su contra, no sólo por parte de autoridades públicas, sino del conjunto del resto del sistema social.

Desde un punto de vista externo, dichos complejos habitacionales cargan con el imaginario de un lugar peligroso, un "aguantadero" para los delincuentes, imagen que lo representa como un lugar encerrado donde sólo quienes comparten esos valores pueden ingresar allí y habitarlo. Así, no se le distinguen territorios, zonas, lugares diferenciales dentro de esos enormes paredones.

Pero existen, dentro del complejo habitacional, modos particulares de relacionarse las distintas organizaciones que, aunque sus objetivos varían entre sí, están todas basadas en lazos orientados a la consecución de fines comunes. Estas organizaciones permiten diferenciar el espacio a través de las relaciones que establecen a diario entre ellas y al interior de cada una, lo que da lugar a una dinámica particular dentro de ese espacio físico.

En estas organizaciones no se agota la complejidad del conflicto que se reedita a diario en este barrio, pero sí, en éstas, operan ciertos códigos que a la vez de identificarse mutuamente como "enemigos", comparten ciertos mecanismos de "violencia" que hace que los demás habitantes le teman. Mecanismos que se expresan a través de innumerables conflictos y continuas relaciones de alianzas, lo que las vuelve, a estas organizaciones, ambiguas y de difícil comprensión para los que no participan directamente en ellas.

En cada una de estas organizaciones, la figura del líder o presidente pareciera que es quien imprime diferentes sentidos a las prácticas y relaciones entre sus miembros al interior de cada territorio. A su vez, éste es quien define el recurso por el cual luchar, ya que los beneficios de su obtención se distribuirán hacia su "grupo íntimo".

En el discurso de estos grupos, aparece la idea de "enemigo" con el cual no es posible convivir ni compartir espacios territoriales, aunque el sentido de pertenecer y trabajar en cada uno de los grupos encuentra nuevo sentido al existir este otro y por la posibilidad de vincularse con él.

Pareciera entonces, que el "gobierno del territorio", delimitación formal y simbólica en tanto imposición de normas del complejo habitacional y las zonas al interior de éste, se constituye en la base del conflicto en tanto control, delimitación y resignificación de prácticas y representaciones. Éstas se van desdibujando en las innumerables relaciones diarias, las cuales redundan en la percepción de inseguridad que tienen los habitantes de dicho espacio urbano.
Pero son estas mismas fronteras las que se van desdibujando en los "arreglos" institucionales y cotidianos entre los distintos grupos, reconociéndose miembros de uno y otro grupo insertos y vinculados a través de alianzas, y a su vez, atravesados por mecanismos de presión, extorsión, amenaza, y silenciamiento.

Estos mecanismos fundan diferentes prácticas políticas conviviendo al interior de un mismo espacio urbano, sostenidas por discursos y prácticas de, sobre todo, el líder de las organizaciones sociales - formales.

Así y todo, la organización y gestión de los problemas comunes al interior del complejo se constituye en un punto importante a analizar, ya que más allá de la organización formal que conlleva este tipo de organización, en este caso llamados Consorcios, permite entrever algunas otras cuestiones ligadas al uso y ocupación política del espacio urbano.

Los espacios colectivos, los espacios de todos o que muchos usan, no son de por sí modalidades de emancipación o de liberación. Sin embargo, son espacios cuyo uso puede ser ligado al emerger de una estructura de relaciones sociales (grupo, movimiento, partida, asociación etc.) capaz de actuar para la satisfacción de necesidades que los miembros de la propia estructura reconocen como comunes, a través del intercambio de información y la confrontación de las experiencias. Por lo tanto, estos espacios son también aquellos en donde el conflicto social latente se vuelve manifiesto, en la forma de choque entre intereses contrastantes (SIGNORELLI, 1999, p. 51).

\subsection{Los Consorcios en El Matadero}

El Matadero se divide en tres bloques 1, 2 y 3. Cada uno de estos bloques está organizado como "consorcio", organización de tipo vecinal, por la participación directa tanto en lo que respecta a la elección del administrador como los asuntos pertinentes a su zona, siendo a su vez un tipo de representación y gestión para la administración de los problemas comunes.

Los consorcios están regulados formalmente por la Ley n. 13.512/1948 de Propiedad Horizontal ${ }^{3}$ cuya dirección recae en un consejo de administración, encabezado por un administrador, elegidos y legitimados por la asamblea de propietarios. Esta última constituye el elemento más dinámico y democrático de dicha institución, al ser la que aprueba o desaprueba decisiones, y elige mediante voto al consejo de administración y al administrador ${ }^{4}$.

Pero en esta manera de administración que podría definirse, en principio, como de autonomía relativa, dado que no escapa a la ambigüedad de quedar atrapada por la vinculación con el estado local y nacional, se encuentran, por un lado, las formas institucionalizadas 
enmarcadas en la Ley de Propiedad Horizontal - la que rige la administración de consorcios -, y por otro, el intento de construcción al interior de cada uno de los consorcios, es decir, formas autónomas de participación y decisión que, por momentos y por experiencias, escapan a los requisitos formales.

Este es un punto importante de la gestión y modo de involucrarse del Instituto Provincial de la Vivienda, dado que se proponía una nueva forma de sociabilidad para los adjudicatarios. A su vez, representaba para el mismo Instituto una manera de delegar negativamente poder, y así no tener ninguna responsabilidad pública frente a los conflictos que se generaran al interior del barrio, tanto ediliciamente como de convivencia, adquiriendo una forma privada (aunque regulada por la Ley de Propiedad Horizontal) no estatal.

De esta manera se constituye en un sistema ambiguo, una formalización comunitaria superpuesta con una legislación de estricta propiedad privada, que en muchos casos es expresada tan solo en escrituras de un bien formal. Esto se debe a que los límites de propiedad de los conjuntos resultan difusos.

Además, es importante no perder de vista el momento en el que se lleva adelante esta "política de participación" - nada menos que el período de dictadura militar - así, cobra mayor significación esta propuesta de "democracia hacia adentro" del complejo, volviéndose una "ficción" con relación a la situación nacional. Ficción en tanto se proponía que los nuevos beneficiarios sean los encargados de decidir y acordar "la organización política-administrativa" del espacio. Esto aparece como una fuerte contradicción en las narrativas de quienes participaron en ese momento, ya que los únicos recursos con los que se contaban, eran el voto y el temor.

$\mathrm{Si}$ se tiene en cuenta que las familias que fueron seleccionadas como adjudicatarias no provenían del mismo espacio territorial ni social, y que esta nueva propuesta de habitabilidad no era el resultado de una demanda colectiva, sino más bien individual-familiar, se puede decir que la formalización de una organización de tipo vecinal con esas características era una novedad. Sin embargo, para más de una familia resultó ser una imposición o requisito para vivir en la ciudad.

El espacio de poder que se construye a partir de ganar o poseer la administración es un factor que moviliza y que posibilita desde la intolerancia o el disenso la creación de propuestas de resistencia y de remoción de las autoridades consorciales.

Las administraciones de los consorcios constituyen los espacios ganados y cedidos por los administradores de turno que, a su vez, no sólo permiten la participación de los consorcistas en la toma de la palabra, sino que se plantea de manera ampliada, valiéndose de otros instrumentos no tan formales para la toma de decisión, aunque ésta sea para destituir a un administrador.
Vale decir que quien asume tal posición dentro de un consorcio organiza y da sentido a un cierto orden, una cierta manera de vincularse con dicha institución, organizarse y vivir dentro de "su" sector. Este es un punto fundamental que permite trazar líneas no sólo en el sentido geográfico, sino en la configuración de espacios simbólicos, siendo entonces "el administrador" una figura conflictiva o posibilitadora dentro del consorcio donde lleva adelante su gestión quien además vincula formalmente el espacio interior con el exterior del consorcio.

\section{A modo de conclusiones}

En tanto construcción del territorio, es posible encontrar distintas divisiones territoriales no siempre coincidente unas a otras; así los límites barriales, distritales se esfuman en nuevas marcaciones, nuevas zonas dentro del mapa social y representacional por aquellos que la habitan como por aquellos que la transitan. Estas superposiciones de miradas y divisiones de un mismo territorio nos permite pensar, en principio, que es difícil encontrar zonas estáticas o rigidizadas donde exista un adentro que, de una vez, clausure su vinculación con un afuera.

La política habitacional Fonavi, analizada en la singularidad del Complejo, no solo nos permite pensar que desde sus orígenes establecía modos y modelos de construcción de vivienda colectiva con diseños cerrados, sino también que reglamentaba modos y maneras de habitarlo, desde su dibujo, los modos de acceso, las formas organizacionales para la resolución o administración de los recursos en común, y el vínculo entre todos los actores involucrados en dicha política. También estas ideas de construcción masiva implicaba una determinada visión del espacio, propio de ese momento histórico, siendo uno de sus supuestos fuertes la relación de determinación entre el espacio habitado en el concepto de la ciudad y la población que allí residiría, marcando grandes zonas dentro de la trama urbana, como también la idea de vecindad que se daría por el solo hecho de vivir en un mismo espacio

Lo interesante ha sido encontrar en la puesta en práctica de dicha política diferencias, ausencias, y modos de gestionarse que permiten vulnerar los textos rígidos de una misma política, esta vez nacional.

Estas organizaciones rompen con la homogeneización estática al distinguir, dentro de un complejo habitacional, grupos, espacios, intereses, discursos y conflictos que delimitan nuevas zonas simbólicas por encima de las marcas físicas y, junto con esto, la marca de un "adentro" tan heterogéneo y complejo como la de un "afuera".

Al entender las relaciones que dan lugar a la conformación de las distintas organizaciones en ese 
espacio habitacional como relaciones más complejas, se hace imprescindible analizarlas como relaciones construidas en una tensión permanente entre lo que podría llamarse un "afuera" y un "adentro", tanto al interior de cada uno de los grupos como las relaciones que éstos sostienen con un "afuera extra barrial".

\section{Referencias}

BOURDIEU, P. Miseria del mundo. Buenos Aires: Fondo de Cultura Económica, 1999.

GIGLIA, A. Vecinos e instituciones. Cultura ciudadana y gestión del espacio compartido. In: CANCLINI, N. (Coord.). Cultura y comunicación en la ciudad de México. Modernidad, multicultarilidad, la ciudad de México a fin de siglo.México, D. F: Universidad Autónoma Metropolitana, 1998. (v. 1).

KESSLER, G. De proveedores, amigos, vecinos y barderos: Acerca del trabajo, delito y sociabilidad en jóvenes del Gran Buenos Aires. In: MURMIS, M. et al. Sociedad y sociabilidad en la Argentina de los Noventa. Buenos Aires: Biblos, 2002, p. 137-170.

OSLACK, O. Merecer la ciudad. Los pobres y el derecho al espacio urbano. Buenos Aires: Humanitas/ Cedes, 1985.

PUEX, N. Las formas de la violencia en tiempos de crisis: Una Villa Miseria del Conourbano Bonaerense. In: ISLA, A.; MÍGUEZ, D. (Comp.). Heridas urbanas. Violencia delictiva y transformaciones urbanas en los Noventa. Buenos Aires: Flacso, 2003, p. 35-70.

REGUILLO, R. Sociabilidad, inseguridad y miedos. Una trilogía para pensar la ciudad contemporánea. Buenos Aires: CIE-UNSAM, 2005.

ROSSINI, G. Vagos, pibes chorros y transformaciones de la sociabilidad en tres barrios periféricos de una ciudad Entrerriana. In: ISLA, A.; MÍGUEZ, D. (Comp.). Heridas urbanas. Violencia delictiva y transformaciones urbanas en los Noventa. Buenos Aires: Flacso, 2003, p. 71-115.

SIGNORELLI, A. Antropología urbana. UAM México: Anthropos Editorial, 1999.

WACQUANT, L. Cárceles de la miseria. Buenos Aires: Manantial, 2000.

Parias urbanos. Marginalidad en la ciudad a comienzo del milenio. Buenos Aires: Manantial, 2001.

. Los condenados de la ciudad. Gueto, periferia y Estado. Buenos Aires: Siglo XXI Editores, 2007.

\section{Notas}

1 Este ensayo se basa en la documentación de la investigación empírica y bibliográfica compilada por el trabajo de campo que se desarrolló en un complejo habitacional Fonavi de la ciudad de Mar del Plata durante los meses de septiembre de 2002 a julio de 2003. En la investigación original, presentada al Doctorado en Humanidades y Artes, mención Antropología, Facultad de Humanidades y Artes, Universidad Nacional de Rosario, se ha cumplido con todos los principios éticos y normas regulatorias para la investigación con seres humanos con el fin de garantizar el anonimato de los entrevistados y referencias espaciales o institucionales. Así, los nombres reales de las personas entrevistadas como del barrio fueron cambiando para respetar su identidad.

2 Disponible en: <http://www.dnrpi.jus.gov.ar/normativa/ ley21581.htm>. Acceso en: 15 jun. 2010.

3 Disponible en: <http://www.ligadelconsorcista.org/ ley13512>. Accesoen: 15 jun. 2010.

4 La formación de consorcios por grupos de viviendas está incluida en las Normas Fonavi (R098/87). Donde se considera que a los efectos de compartir el mantenimiento y control de los espacios exteriores comunes, el diseño adoptado deberá posibilitar la definición y distribución de sectores en cada bloque.

\section{Silvana Martino}

martino@cifasis-conicet.gov.ar

Doctora en Antropologia, Universidad Nacional de Rosario

Becaria Pos doctoral, Centro Internacional Franco Argentino de Ciencias de la Información y de Sistemas, Consejo Nacional de Investigaciones Científicas y Técnicas (Conicet-Cifasis)

\section{Cifasis}

27 de Febrero 210 bis

S2000EZP

Rosario - República Argentina 